Sharif University of Technology
Scientia Iranica
SCIENTIA
IRAN ICA
http://scientiairanica.sharif.edu

\title{
Evaluation of effective parameters in lateral buckling of subsea pipelines on a rigid seabed
}

\author{
M. Vaghefi ${ }^{\mathrm{a}, *}$, M. Keshavarzi ${ }^{\mathrm{b}}$, and M. Akbari ${ }^{\mathrm{a}}$ \\ a. Department of Civil Engineering, Persian Gulf University, Shahid Mahini Street, Bushehr, P. O. Box 75169-13817, Iran. \\ b. Vocational Department, Alzahra University, Qods Square, Bushehr, P.O. Box 75135-1673, Iran. \\ Received 7 September 2015; received in revised form 23 August 2016; accepted 11 March 2017
}

\section{KEYWORDS \\ Subsea pipeline; \\ Lateral buckling; \\ Initial imperfection; \\ Internal pressure; \\ Temperature.}

\begin{abstract}
This study investigates the lateral buckling of pipelines on a rigid seabed under temperature and internal pressure, regardless of the effects of waves and currents. The analytical results in some cases are compared with the numerical results obtained from ABAQUS software. Then, the influence of effective parameters (such as internal pressure, friction, initial imperfection, diameter and thickness of the pipe, and the pipe material) on the lateral buckling of pipelines on a rigid seabed is evaluated in order to determine the level of importance. The most important results indicate a reduced possibility of lateral buckling with an increased coefficient of friction between the pipe and seabed, reduction of the internal pressure, and reduction of the amplitude of the initial imperfection in the pipeline. For example, compared to the models with coefficients of friction equal to 0.5 and 0.3 , safety temperatures in the model with a coefficient of friction equal to 0.7 have increased by $13.6 \%$ and $50 \%$. Compared to the models with initial imperfections equal to $0.3,0.5$, and $0.7 \mathrm{~m}$, safety temperatures in the model with an initial imperfection of $0.1 \mathrm{~m}$ have increased by $4.49 \%, 15.32 \%$, and $40.65 \%$.
\end{abstract}

(C) 2018 Sharif University of Technology. All rights reserved.

\section{Introduction}

A pipeline can buckle either upwards ('upheaval buckling') or sideways ('lateral buckling'), similar to column buckling in steel frames. Driving force is a longitudinal compressive force in the pipeline wall and the fluid it contains. In general, the mentioned force has two components: pressure and temperature. If a pipeline is free to move longitudinally, the resultant longitudinal force over a cross-section will be zero, because the longitudinal compressive force in the fluid is balanced by an equal and opposite longitudinal tensile force

\footnotetext{
*. Corresponding author. Tel.: +98 77 31222401;

Fax: +98 rry 33340376

E-mail addresses: vaghefi@pgu.ac.ir (M. Vaghefi);

marjan.keshavarzi@gmail.com (M. Keshavarzi);

m.akbari@pgu.ac.ir (M.Akbari)
}

doi: $10.24200 /$ sci. 2017.4610 in the pipe wall. The longitudinal compressive force in the pipe can lead to global buckling of offshore pipelines. An increase in pipe wall temperature makes the pipe material expand. If the longitudinal movement is prevented or constrained, the material goes into compression, and longitudinal compressive force is created in the pipe. An increase in the internal pressure induces a tensile hoop stress in the pipe wall and an accompanying tensile hoop strain. If the longitudinal movement is prevented or constrained, the material goes into tension; in addition, the longitudinal tensile force is the longitudinal tensile stress in the pipe wall multiplied by the cross-section area of the wall. However, in addition to the tensile force in the pipe wall, there is also longitudinal compressive force in the contents equal to the cross-section of the contents (the internal area of the pipeline), multiplied by the pressure. The longitudinal compressive force in the contents is greater than the longitudinal tensile 
force in the wall; hence, the resultant longitudinal force is compressive [1]. Lateral buckling generally occurs in unburied pipelines, because they often have less resistance to sideways movement than to upward movement. A pipeline moves sideways against the friction of whatever it is lying on, whereas if it lifts upwards, its own weight resists the movement. Many marine pipelines are not trenched or buried; hence, lateral buckling mostly occurs in marine pipelines [2]. The problems that occurred in railway tracks more than 70 years ago, together with the analysis done by Kerr [3], are very closely related to thermal buckling problems in pipelines. Hobbs [4,5] presented a summary of the basic models of buckling in a long pipeline under high temperature and internal pressure on a rigid seabed in 1981 and 1984. Based on the main result found by Hobbs, temperature for lateral buckling is lower than that for vertical buckling and, in fact, indicates higher importance of lateral buckling in comparison with vertical buckling. Taylor and Gan [6] presented an analytical solution for imperfect pipelines in 1986. The results showed a reduction in buckling temperature with the increased amplitude of the initial imperfection. Palmer et al. [7] demonstrated through a small-scale test that the constraint of expansion of a pipeline due to the increasing internal pressure could induce vertical buckling. Peek and Yun [8] presented analytical expressions for triggering such lateral buckles by applying buoyancy to the pipeline. They solved the design problem of establishing the required amount of buoyancy for a given axial load at which the buckle must be triggered. The analytical results were based on a flat seabed, theory of moderately large deflections, and elastic pipe behavior. Wang et al. [9] extended an analytical solution for the vertical pipeline buckling on a rigid seabed to a soft seabed and, then, illustrated and analyzed the effects of soil resistance on pipeline stability, buckling mode, and amplitude. They concluded that if soft soil is detected in a subsea pipeline route, downward buckling may occur, instead of the conventional upheaval buckling. Karampour et al. [10] investigated the lateral and upheaval buckling of subsea pipelines. For lateral buckling, they compared analytical results based on an isolated half-wave length model and the finite-element results from a long pipe with those of a nonlinear pipe-soil interaction model. They concluded that some of the previously published results do not agree with the current analytical and numerical results.

Liu et al. [11] used four numerical simulation methods based on the finite-element method (2D implicit, 2D explicit, 3D implicit, and 3D explicit methods) to simulate the pipeline global buckling in different temperatures. The comparison indicated that the results obtained using the $2 \mathrm{D}$ implicit and $2 \mathrm{D}$ explicit methods were similar, and the results obtained using the 2D implicit method were closer to those obtained using traditional analytical solutions. Karampour and Albermani [12] presented experimental and finite-element results for propagation buckling, pure bending, and buckle interaction in subsea pipelines. They conducted the analysis using both transient and steady-state conditions and, then, highlighted the vulnerability of subsea pipelines to buckle the interaction, particularly in deep waters. Wang et al. [13] studied static and dynamic responses of upheaval buckling of unburied subsea pipelines in both $2 \mathrm{D}$ and $3 \mathrm{D}$. The results showed that for bifurcation of upheaval buckling, the predicted buckling temperatures of those models were all acceptable with an error of $5 \%$. Hong et al. [14] proposed a lateral global buckling failure envelope for deep-water high-temperature and high-pressure pipelines using a numerical simulation analysis. They concluded that pipelines with larger diameters, larger soil resistance coefficients, larger calculating lengths, and thinner wall thicknesses were more likely to fail after buckling. Feng et al. [15] reported the experimental investigation of a method used for distributed detection of lateral buckling in subsea pipelines with a Brillouin fiber optic sensor. They validated the feasibility of the method by using an experimental program on a small-scale model pipe. The results demonstrated that the proposed approach was able to detect the onset and progress of lateral buckling in the pipelines. Li et al. [16] deduced an analytical solution for the lateral buckling in the entire design region. RSM was adopted to improve the numerical stability and calculation efficiency. They presented a framework for buckling control using distributed buoyancy sections and demonstrated several illustrative examples, proposing that the method has high efficiency and accuracy in solving the problem of the lateral buckling control. Shahandeh and Showkati [17] investigated buckling and post-buckling behavior of ring-stiffened pipelines on a small scale through experiments and the Finite-Element Method (FEM). Their results indicated that increasing the number of ring-stiffeners greatly increases the buckling capacity and lateral displacement of the pipeline. Zhang et al. [18] established Finite-Element Models for imperfect PIP systems on the basis of 3D beam element and tube-to-tube element in ABAQUS. They conducted a parametric study of the effect of these parameters on the critical axial force and post-buckling forms. These parameters include structural parameters (such as imperfections, clearance, and bulkhead spacing), pipe/soil interaction parameters (such as axial and lateral friction properties between pipeline and seabed), and the load parameter's submerged weight. They used Python as a programming language to realize parametric modeling in ABAQUS. Some of their conclusions were obtained that can provide a guide for the design of PIP pipelines. 
Table 1. Constants for lateral buckling modes [4].

\begin{tabular}{cccccc}
\hline & \multicolumn{5}{c}{ Constants } \\
\cline { 2 - 6 } Mode & $\boldsymbol{K}_{\mathbf{1}}$ & $\boldsymbol{K}_{\mathbf{2}}$ & $\boldsymbol{K}_{\mathbf{3}}$ & $\boldsymbol{K}_{\mathbf{4}}$ & $\boldsymbol{K}_{\mathbf{5}}$ \\
\hline 1 & 80.76 & $6.391 \times 10^{-5}$ & 0.5 & $2.407 \times 10^{-3}$ & 0.06938 \\
2 & $4 \pi^{2}$ & $1.743 \times 10^{-4}$ & 1.0 & $5.532 \times 10^{-3}$ & 0.1088 \\
3 & 34.06 & $1.668 \times 10^{-4}$ & 1.294 & $1.032 \times 10^{-2}$ & 0.1434 \\
4 & 28.20 & $2.144 \times 10^{-4}$ & 1.608 & $1.047 \times 10^{-2}$ & 0.1483 \\
$\infty$ & $4 \pi^{2}$ & $4.7050 \times 10^{-5}$ & $4.4495 \times 10^{-3}$ & 0.05066 \\
\hline
\end{tabular}

In this study, the lateral buckling of pipelines on a rigid seabed under temperature and internal pressure is discussed regardless of the effects of waves and currents. The analytical results in some cases are compared with the numerical results obtained from ABAQUS software. Then, the influence of effective parameters on lateral buckling of the pipelines on a rigid seabed is evaluated in order to determine the level of importance. The parameters affecting the pipeline lateral buckling, such as internal pressure, friction, initial imperfection (for different imperfection amplitudes), diameter, thickness, and the material of the pipe on the safety temperature, the axial expansion, the buckling amplitude, and the effective axial force, are examined.

\section{The equations governing the lateral buckling of offshore pipelines on a rigid seabed}

This paper introduces the analytical solutions proposed by Hobbs for lateral buckling. Hobbs [4] presented a summary of basic buckling models in a long pipeline. In the model, the cross-sectional area of the pipe is denoted by $A$, Young's Modulus by $E$, the coefficient of linear thermal expansion by $\alpha$, the pipe wall thickness by $t$, the pipe radius by $r$, and the temperature change by $\Delta T$; the force created by the full restraint of thermal expansion is as follows:

$$
P_{0}=E A \alpha \Delta T \text {. }
$$

The free axial strain, $\varepsilon$, due to a positive pressure difference, $p$, between the fluid pressure in the pipe and the external pressure is as follows:

$$
\varepsilon=\frac{1}{E}\left(\frac{p r}{2 t}-v \frac{p r}{t}\right)
$$

where $v$ is the Poisson's ratio. The force created by the full restraint of the axial strain is follows:

$$
P_{0}=\frac{A p r}{t}(0.5-v) \text {. }
$$

Figure 1 shows various modes of buckling of the pipeline. The equations proposed by Hobbs for modes 1 to $\infty$ of buckling are as follows:
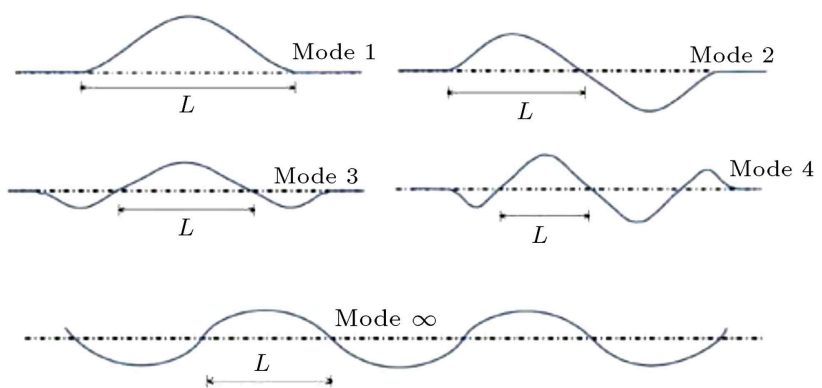

Figure 1. Lateral buckling modes [19].

$$
\begin{aligned}
& P=k_{1} \frac{E I}{L^{2}}, \\
& P_{0}=P+k_{3} \varphi w L\left[\left(1.0+k_{2} \frac{A E \varphi w L^{5}}{(E I)^{2}}\right)^{1 / 2}-1.0\right],
\end{aligned}
$$

where $P$ is the axial load in the buckle, $P_{0}$ is the axial load away from the buckle, $\varphi$ is the coefficient of friction between pipe and subgrade, $L$ is the buckle length, and $w$ is the submerged weight of the pipeline.

Maximum amplitude of buckle, $\hat{y}$, buckle length for the minimum axial load away from buckle, $\tilde{L}$, and maximum bending moment, $\hat{M}$, at $x=0$, are presented as follows, and the constants for the lateral buckling modes are presented in Table 1:

$$
\begin{aligned}
& \hat{y}=k_{4} \frac{\varphi w L^{4}}{E I}, \\
& \tilde{L}=\left[\frac{2.7969 \times 10^{5}(E I)^{3}}{(\varphi w)^{2} A E}\right]^{0.125}, \\
& \hat{M}=k_{5} \varphi w L^{5} .
\end{aligned}
$$

\section{Geometry and materials considered for the pipeline}

The design parameters of the pipeline for an analytical solution and a numerical evaluation in this paper are shown in Table 2. The steel pipe is an API 5L X65 grade oil pipeline. This type of steel is named by the American Petroleum Institute. The concrete is used as pipe protective coating. The properties of the steel are listed in Table 3. 
Table 2. Design parameters of pipeline for analytical solution and numerical evaluation [4].

\begin{tabular}{cccccc}
\hline $\begin{array}{c}\text { Pipe outside } \\
\text { diameter } \\
(\mathbf{m m})\end{array}$ & $\begin{array}{c}\text { Pipe wall } \\
\text { thickness } \\
(\mathbf{m m})\end{array}$ & $\begin{array}{c}\text { Cross sectional } \\
\text { area } \\
\left(\mathbf{c m}^{\mathbf{2}}\right)\end{array}$ & $\begin{array}{c}\text { Second moment } \\
\text { of area } \\
\left(\mathbf{c m}^{\mathbf{4}}\right)\end{array}$ & $\begin{array}{c}\text { Submerged } \\
\text { weight } \\
(\mathbf{k N} / \mathbf{m})\end{array}$ & $\begin{array}{c}\text { Internal } \\
\text { pressure } \\
(\mathbf{M P a})\end{array}$ \\
\hline 650 & 15 & 299.2 & 150900 & 3.8 & 6 \\
\hline
\end{tabular}

Table 3. API 5L X65 properties [4].

\begin{tabular}{ccccc}
\hline $\begin{array}{c}\text { Density } \\
\left(\mathbf{k g} / \mathbf{m}^{3}\right)\end{array}$ & $\begin{array}{c}\text { Yield stress } \\
(\mathbf{M P a})\end{array}$ & $\begin{array}{c}\text { Young index } \\
\left(\mathbf{k N} / \mathbf{m m}^{\mathbf{2}}\right)\end{array}$ & $\begin{array}{c}\text { Expansion } \\
\text { coefficient }\end{array}$ & $\begin{array}{c}\text { Poisson's } \\
\text { ratio }\end{array}$ \\
\hline 7850 & 448 & 210 & $11.7 \times 10^{-6}$ & 0.3 \\
\hline
\end{tabular}

Table 4. The results of the lateral buckling calculations.

\begin{tabular}{ccccccc}
\hline $\begin{array}{c}\text { Buckling } \\
\text { mode }\end{array}$ & $\begin{array}{c}\text { Buckle } \\
\text { length } \\
\boldsymbol{L}(\mathbf{m})\end{array}$ & $\begin{array}{c}\text { Amplitude } \\
\hat{\boldsymbol{y}}(\mathbf{m})\end{array}$ & $\begin{array}{c}\text { Moment } \\
\hat{\boldsymbol{M}}(\mathbf{k N} / \mathbf{m})\end{array}$ & $\begin{array}{c}\text { Axial } \\
\text { force } \\
\boldsymbol{P}(\mathbf{k N})\end{array}$ & $\begin{array}{c}\text { Bending plus } \\
\text { axial stress } \\
\left(\mathbf{N} / \mathbf{m m}^{\mathbf{2}}\right)\end{array}$ & $\begin{array}{c}\text { Percentage } \\
\text { of yield if }\end{array}$ \\
$\begin{array}{c}\boldsymbol{\sigma}_{\boldsymbol{y}=\mathbf{4 4 8}} \\
\left(\mathbf{N} / \mathbf{m m}^{\mathbf{2}}\right)\end{array}$ \\
\hline 2 & 80 & 1.31 & 1323 & 1926 & 350 & 78 \\
3 & 75.3 & 2.07 & 1335 & 1876 & 395 & 88 \\
\hline
\end{tabular}

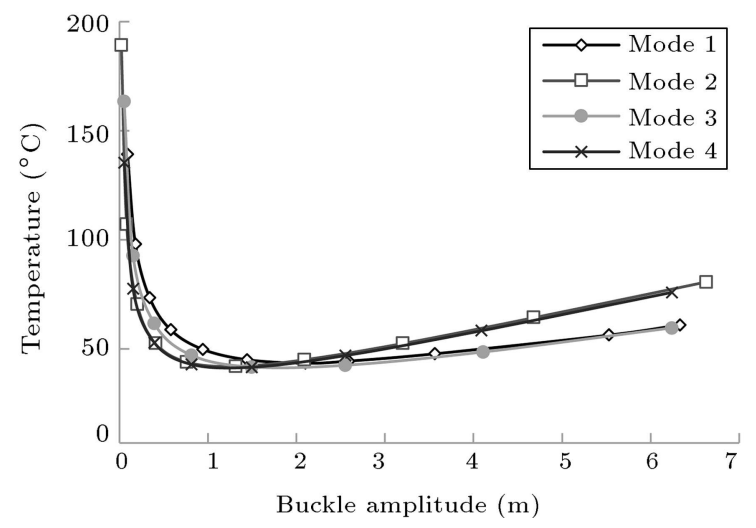

Figure 2. Temperature difference versus buckle amplitude.

\section{Analytical solution}

Figures 2 and 3 show the results of the lateral buckling of pipelines with the parameters listed in Tables 2 and 3 , on a rigid seabed under internal pressure and temperature, using Hobbs equations and assuming a friction coefficient of 0.5 .

Figure 2 shows that buckles in mode 3 are possibilities at $42^{\circ} \mathrm{C}$. Given the buckle amplitude shown in Figure 2 at the beginning of the buckling, the values of buckle length, bending moment, and the axial force can be calculated using Eqs. (7), (8), and (4), respectively. The results of these calculations are included in Table 4. By comparing the resulting stress with the yield point of an API X65 grade line, mode 3 is clearly the most critical one with $88 \%$ yield. In addition, maximum buckle amplitude and maximum bending stress occur in this mode.

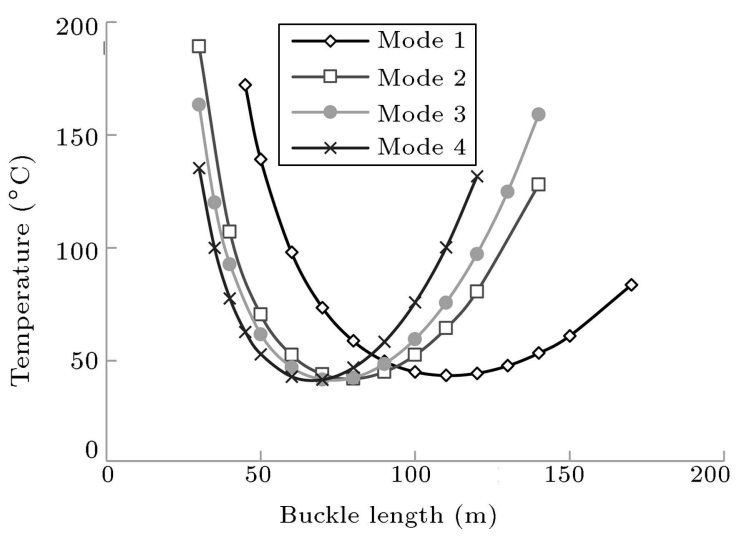

Figure 3. Temperature difference versus buckle length.

\section{Modeling the problem using ABAQUS software}

In order to ensure the accuracy of the modeling, first, the finite-element model of the pipe, whose geometry is presented in Table 2 and material properties listed in Table 3, examined in the section of analytical solution, is modelled using ABAQUS finite-element software [20] for the lateral buckling mode of pipelines on a rigid seabed. Then, the results obtained from the software are compared with those obtained from the analytical solution.

\subsection{Geometry of the model}

A 5-km-long pipeline is considered for modeling. Beam elements are used to model the pipe. Beam elements are used when one dimension of the desired construction (length) is significantly higher than the other two dimensions. It is necessary that the cross-sectional 
dimensions of the construction be 0.1 times smaller than the length so that the beam theory can provide acceptable solutions. Regarding the beam's elements, it is assumed that the planes perpendicular to the beam axis remain as planes after deformation. In the modeling, the seabed is assumed an analytical rigid surface. Using analytical rigid seabed significantly reduces the size of computations. Since rigid seabed is considered without any elevation or degradation, this paper proposed the use of this kind of seabed.

\subsection{Initial imperfection in the pipe}

No buckling occurs in a direct pipeline, which has no out-of-straightness. In order to generate buckling in the pipe, an initial imperfection with the length of 100 meters and amplitude of $10 \mathrm{~cm}$ is applied to the pipe. In order to generate imperfection in the pipe, the pipe-buckling modes should be carried out using buckle analysis. The initial imperfection is shown in Figure 4, which is plotted for $1000 \mathrm{~m}$ in the middle of the pipe. Then, the static risk analysis is applied. The analysis procedure is based on the non-linear buckling analysis.

\subsection{Pipe-soil interaction}

The interaction between pipe and soil is modeled by the definition of the friction between the pipe and the seabed. The Coulomb model is used to model the frictional behavior of the soil. The friction coefficients in both axial and transverse directions are assumed identical in the presented equations, and the coefficient

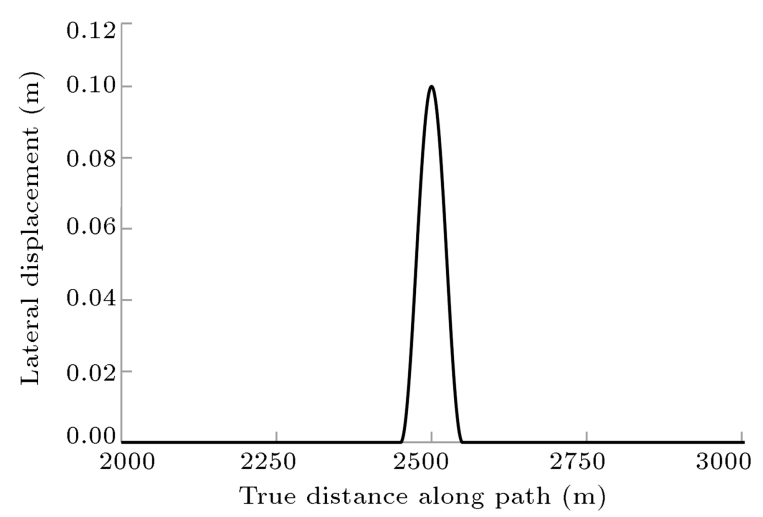

Figure 4. Initial horizontal out-of-straightness. of friction in both directions is chosen as 0.5. Hence, this type of modeling may increase the computations; however, it is the best option to model the pipe in its actual length.

\subsection{Loading and boundary conditions}

Degree of freedom is constrained at both ends of the pipeline in order to apply loading. The internal pressure is applied to the pipe and the temperature is increased along the pipe. Temperature rise induces the axial force in the pipe; however, it does not deform the pipe before buckling. The initial seabed temperature is assumed $13^{\circ} \mathrm{C}$, which is increased up to $90^{\circ} \mathrm{C}$.

\subsection{Pipe's element}

According to DNV standard recommendation, the length should typically be in the order of one diameter, where the buckle is expected to occur and may be longer in straight portions [21]. Therefore, elements with a $0.5 \mathrm{~m}$ length are selected for the entire pipe in the modeling. The pipe is $5 \mathrm{~km}$ long, and each element is $0.5 \mathrm{~m}$ long (10000 elements). For elements smaller than $0.5 \mathrm{~m}$, the response would not vary. PIPE31 element is used for the pipes. This element is a twonodal three-dimensional element. It has a thin-walled circular cross-section, which has the capability to apply internal pressure [19].

\subsection{Results of analysis}

The result of the lateral buckling modeling of the pipeline in ABAQUS at the beginning of the buckling is shown in Figure 5. As seen in the figure, the maximum bending stress in the pipeline buckle section is lower than the yield stress of steel.

Figure 6 shows the relationship between the temperature and the amplitude of buckling in the lateral buckling analysis obtained from the analytical result and the numerical analysis. The resulting curve is Ushaped. This means that there are two possible buckle lengths for one temperature change. If the initial imperfection were small in the pipe, the figure would be U-shaped. The branch A-B is actually an unstable equilibrium path. The stable equilibrium path begins when the temperature is $45.15^{\circ} \mathrm{C}$ and the buckling

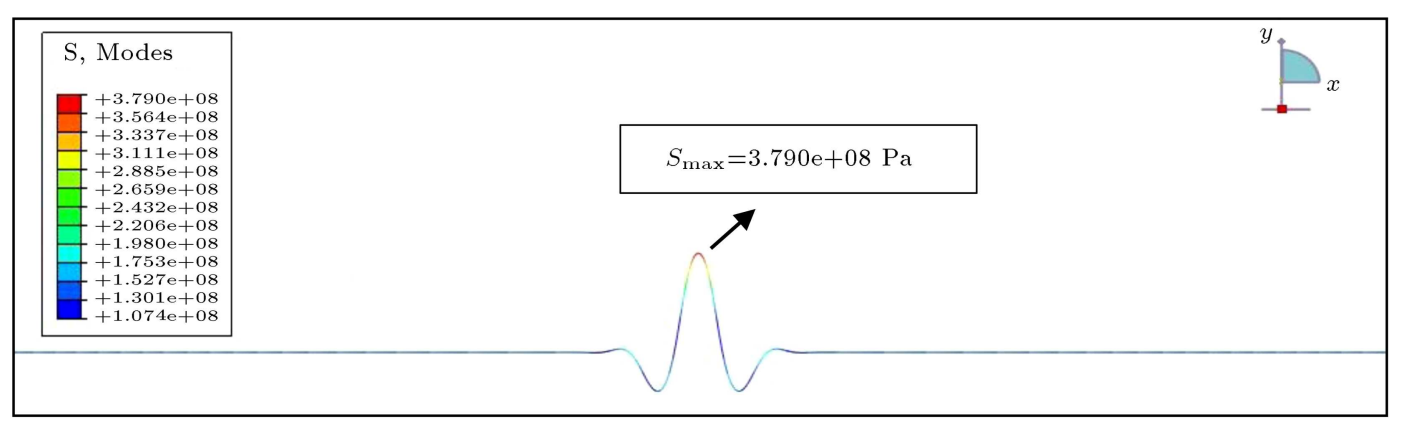

Figure 5. Result of lateral buckling modeling of the pipeline in ABAQUS. 


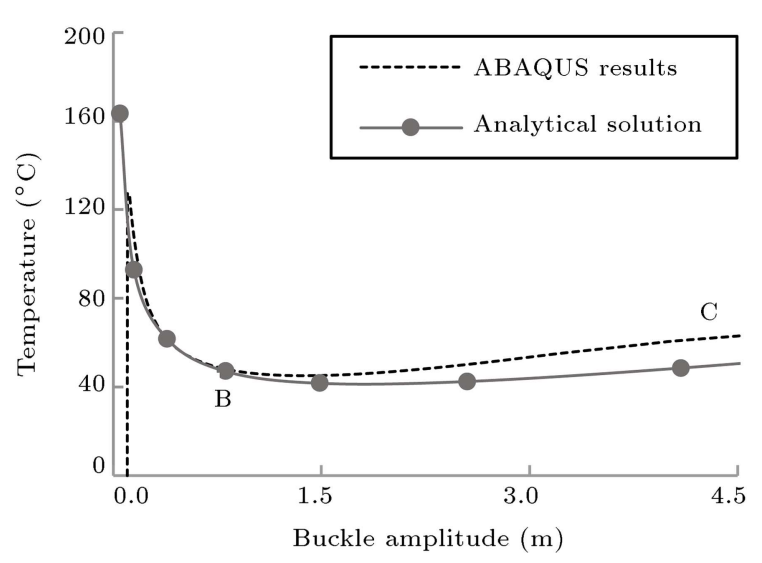

Figure 6. Temperature difference versus buckle amplitude.

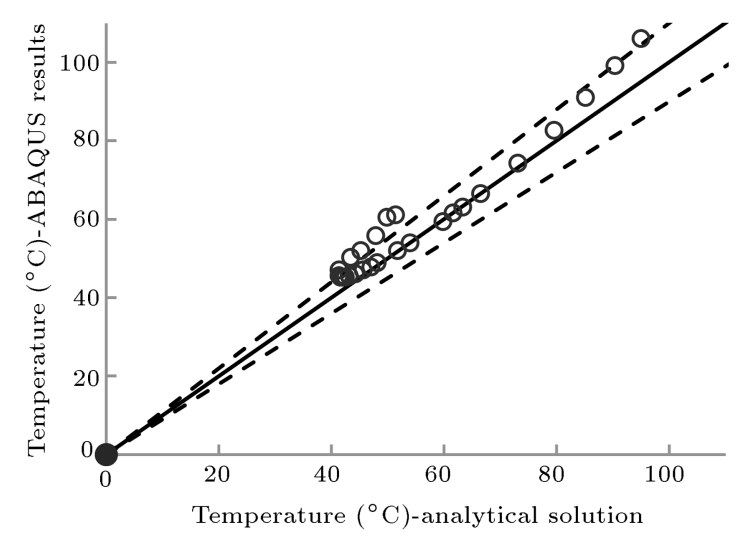

Figure 7. Error in safety temperature.

amplitude equals $1.27 \mathrm{~m}$. The temperature at which a stable equilibrium path starts, i.e. the minimum temperature at which the lateral buckling begins, is called the safety temperature. Branch B-C is a stable equilibrium path. In fact, this is the path at which the buckling occurs in the pipeline, called the post-buckling path.

Figure 7 shows error in temperature versus the buckling amplitude curve obtained from software results, compared to the analytical solution. As shown in the figure, the error is less than $10 \%$, and when the temperature increases, the difference between the two diagrams will be greater. Considering that the analytical equations are proposed for a straight pipeline and according to the fact that the pipeline model has an initial imperfection, the obtained results are acceptable and consistent with those obtained from Hobbs relationships.

Figure 8 shows deformation of the pipe at the beginning of buckling. This figure is drawn for $600 \mathrm{~m}$ in the middle of the pipeline. According to the results obtained from the numerical analysis, it is observed that mode 3 is the prevailing mode.

The pipe buckling amplitude changes due to the heat for unstable equilibrium, as shown in Figure 9(a).

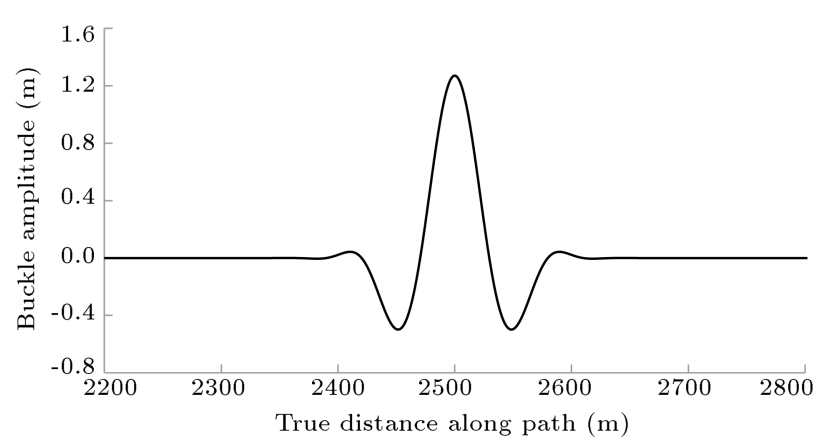

Figure 8. Lateral deformation at the beginning of buckling.

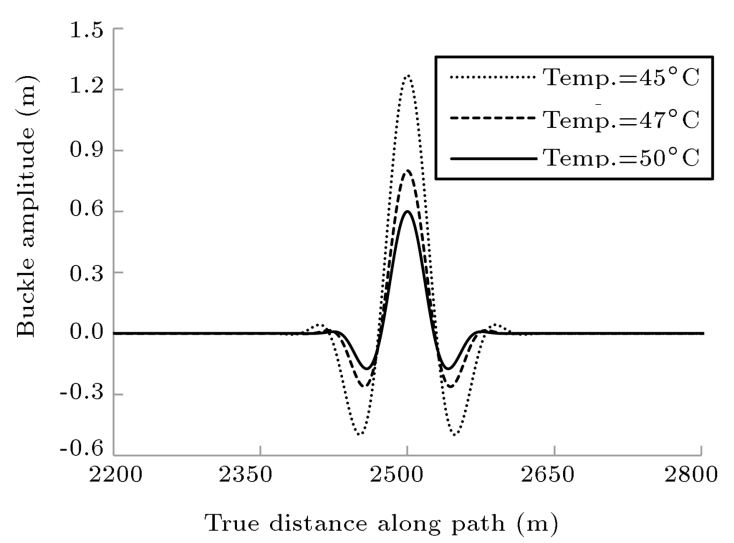

(a)

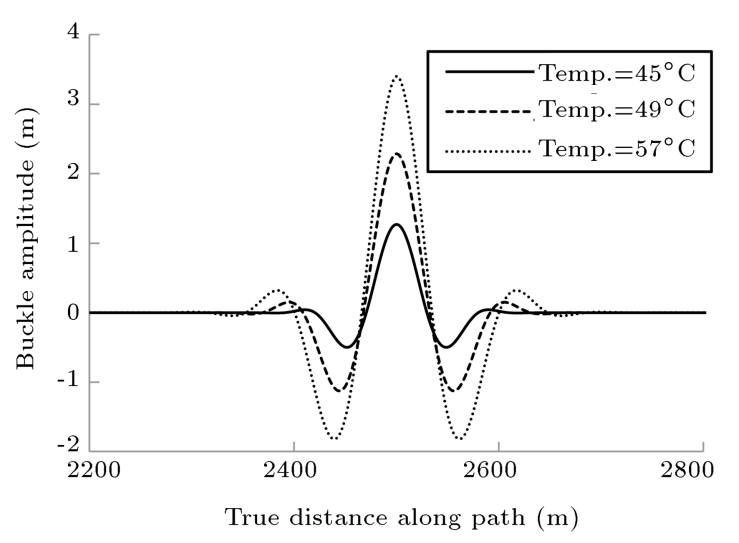

(b)

Figure 9. Buckle shape in lateral buckling of pipeline: (a) Unstable equilibrium path and (b) stable equilibrium path.

According to the figure, if the temperature decreases in unstable equilibrium, the buckling amplitude and length increase. Deformation of the pipe due to temperature difference for stable equilibrium is shown in Figure 9(b). According to the figure, the buckling amplitude and length increase by increasing the temperature.

The pipeline located on the seabed is under the influence of high temperature and pressure and has a tendency for expansion and elongation. If expansion of the pipe is restricted between the pipe and the 


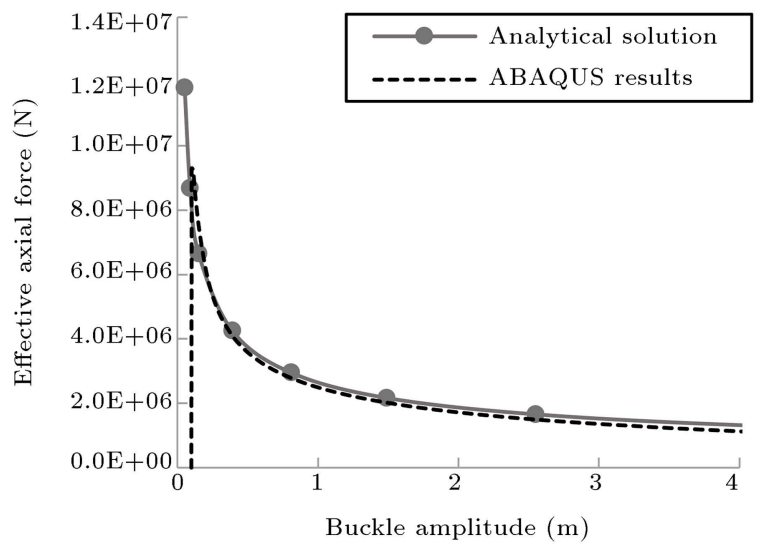

(a)

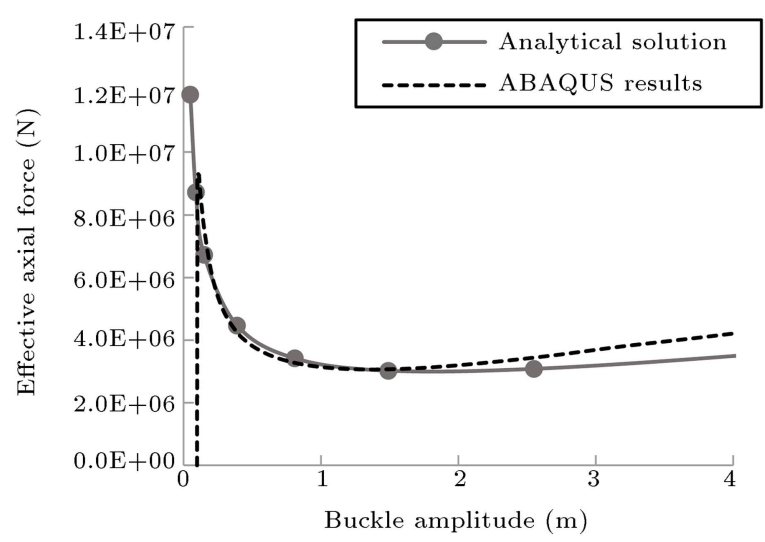

(b)

Figure 10. Effective axial force versus buckling amplitude at: (a) Buckling point and (b) pipe end.

seabed, for example by the friction force, longitudinal axis force will be applied to the pipeline. In this mode, the pipeline is deformed under the compressive axial force applied to the pipe caused by the temperature and pressure loading.

Figure 10(a) shows the effective axial force at the buckling point versus the buckling amplitude obtained from the analytical solutions and the software results. As observed in the figure, the effective axial force decreases during the analysis following the occurrence of the buckling in the pipeline, because the pipeline is axially displaced at the direction of the resulting buckling. Then, the frictional force mobilized due to this displacement decreases and, then, the effective axial force releases. In fact, pipe deformation decreases the effective axial force at the buckling point.

Figure 10(b) shows the effective axial force at a farther point to buckling (the pipe end) versus the buckling amplitude obtained from the analytical solutions and the software results. As can be seen in the figure, the value of the effective axial force at the farther point to buckling at the beginning of buckling (at the stable equilibrium path), according to Hobbs calculations, is calculated as $3.01 \times 10^{6} \mathrm{~N}$, while this

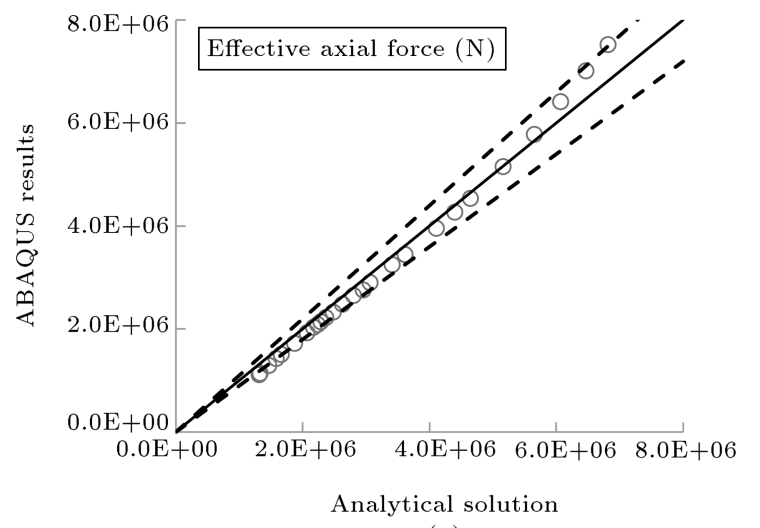

(a)

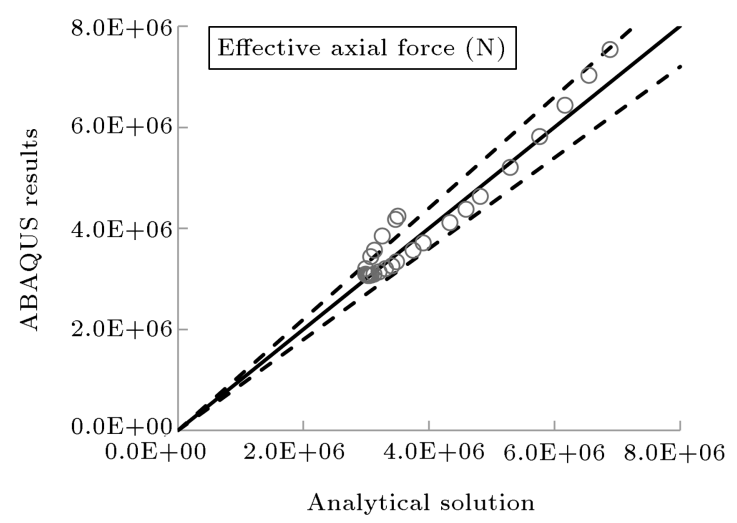

(b)

Figure 11. Error in effective axial force amplitude at: (a) Buckling point and (b) pipe end.

value is obtained as $3.07 \times 10^{6} \mathrm{~N}$ based on the results of modeling. There is a $1.99 \%$ difference between these two values. Changes in the effective axial force at a farther point to buckling are proportional to changes in the temperature along the length of the pipeline. In fact, the value of this force decreases by decreasing the temperature (the unstable equilibrium path), while it increases by increasing the temperature.

Figure 11 shows errors in the effective axial force obtained from the software results compared to the analytical solution method at both the buckling point and the farther point to buckling. According to Figure 11(a), it is observed that the values of the effective axial force at the buckling point initially obtained from both methods are about $10 \%$ different. However, the two graphs almost overlap.

The effective axial force at the father point to buckling obtained by both methods (Figure 11(b)) shows less than $10 \%$ difference relative to each other at the unstable equilibrium path. If the temperature decreases further, there will be less difference between the two graphs until the beginning of the lateral buckling. Then, the two graphs overlap and, with further increase in temperature, there is a greater difference between the two graphs. 


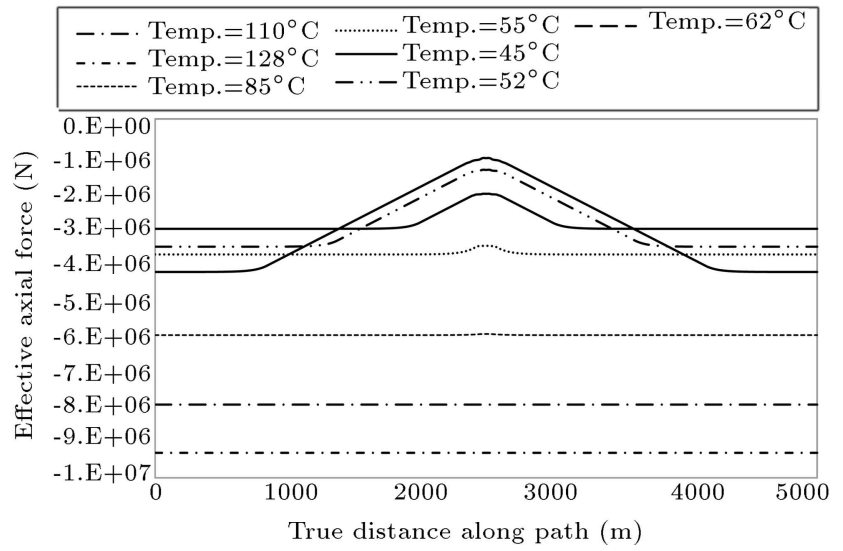

Figure 12. Effective axial force along length of the pipe.

Figure 12 shows the effective axial force along the length of the pipe for different temperatures. In this figure, $110^{\circ} \mathrm{C}$ and $128^{\circ} \mathrm{C}$ occur before the unstable equilibrium path. In this region, the effective axial force increases by increasing the temperature until it reaches the maximum force. Then, the unstable equilibrium starts. In addition, $55^{\circ} \mathrm{C}$ and $85^{\circ} \mathrm{C}$ also refer to the unstable equilibrium path. In this path, the effective axial force decreases by decreasing the temperature. It should be noted that $45^{\circ} \mathrm{C}$ temperature is the safety temperature, which refers to the time that the lateral buckling occurs in the pipe. Then, by increasing the temperature $\left(52^{\circ} \mathrm{C}\right.$ and $\left.62^{\circ} \mathrm{C}\right)$, the effective axial force decreases at the buckling points, while this force increases at the farther point to buckling.

Since the lateral buckling is considerably important in offshore pipelines on a rigid seabed, the influence of several parameters on the lateral buckling is investigated to determine the level of importance. The evaluated parameters of the lateral buckling of the pipeline on a rigid seabed are effect of internal pressure, effect of friction, effect of initial imperfection, effect of diameter and thickness of the pipe, and, finally, effect of pipe material.

\subsubsection{Internal pressure}

The internal pressure to be used in designing a piping system for liquid, gas, or in two phases, shall be larger than the maximum pressure of the operation as well as the pressure resulting from the hydrostatic test. The lateral buckling is studied for three pipe modes regardless of internal pressure, design's internal pressure of $6 \mathrm{MPa}$, and internal pressure of $10 \mathrm{MPa}$.

Figure 13 shows the results of the internal pressure in the pipe. As shown in the figure, increasing internal pressure significantly reduces the safety temperature. In fact, by increasing internal pressure, buckling is more likely to occur. Safety temperature in the main model (internal pressure equal to $6 \mathrm{MPa}$ ) is $45.15^{\circ} \mathrm{C}$. Safety temperatures are equal to $38.84^{\circ} \mathrm{C}$ and $54.62^{\circ} \mathrm{C}$ in models with internal pressure equal to

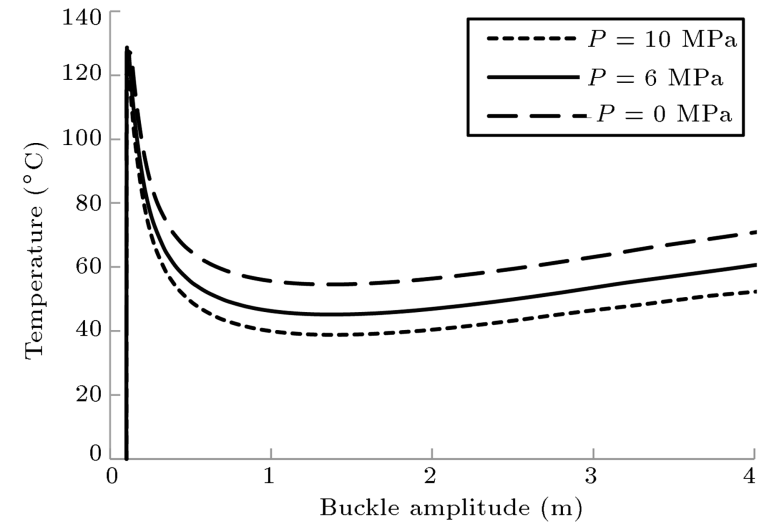

Figure 13. Temperature versus buckle amplitude for different $P$.

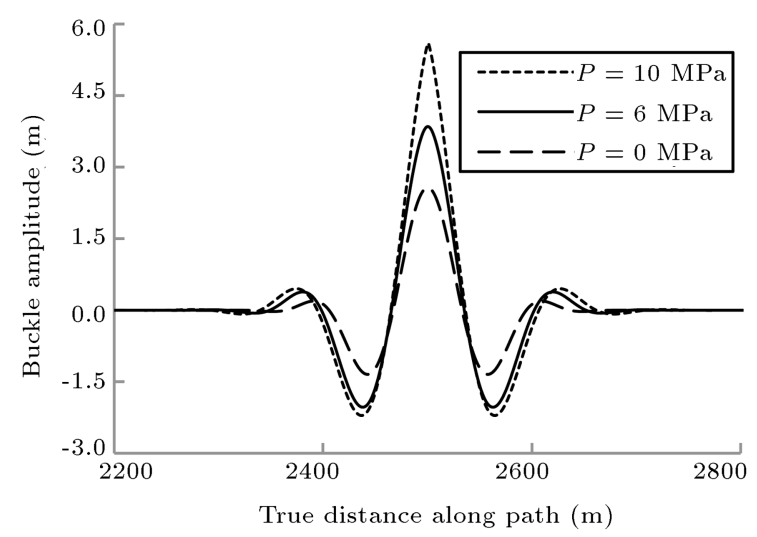

Figure 14. Pipe deformation for different $P$.

$10 \mathrm{MPa}$ and without internal pressure, respectively. The safety temperature in the model without internal pressure has increased by $21 \%$ and $40 \%$, compared to the models with internal pressures equal to $6 \mathrm{MPa}$ and $10 \mathrm{MPa}$.

Increasing pressure has a significant effect on the buckling amplitude, and buckling amplitude increases by increasing pressure. For a better comparison, the buckling amplitude values at $60^{\circ} \mathrm{C}$ are drawn in Figure 14. The buckling length also increases by increasing pressure. The buckling amplitudes in the models with internal pressures equal to $10 \mathrm{MPa}$ and $6 \mathrm{MPa}$ are 5.59 and $3.85 \mathrm{~m}$, respectively. In addition, the buckling amplitude in the model without internal pressure is equal to $2.56 \mathrm{~m}$. The buckling amplitude in the model with internal pressure equal to $10 \mathrm{MPa}$ is respectively 1.45 and 2.17 times higher than those in the models with internal pressure equal to $6 \mathrm{MPa}$ and without internal pressure.

The effect of internal pressure on the axial extension at $60^{\circ} \mathrm{C}$ is shown in Figure 15 . According to the figure, the axial expansion increases by increasing pressure because applying internal pressure leads to a lower temperature to start the buckling. Then, the buckling occurs earlier and the effective force 


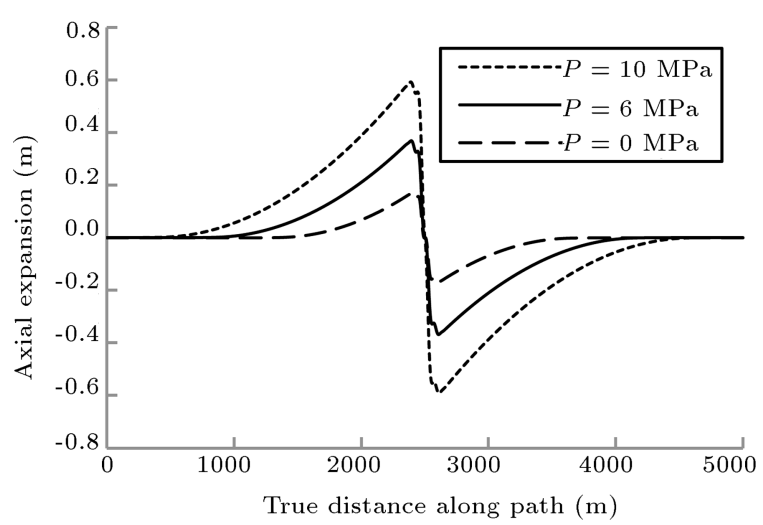

Figure 15. Axial expansion along pipe length for different $P$.

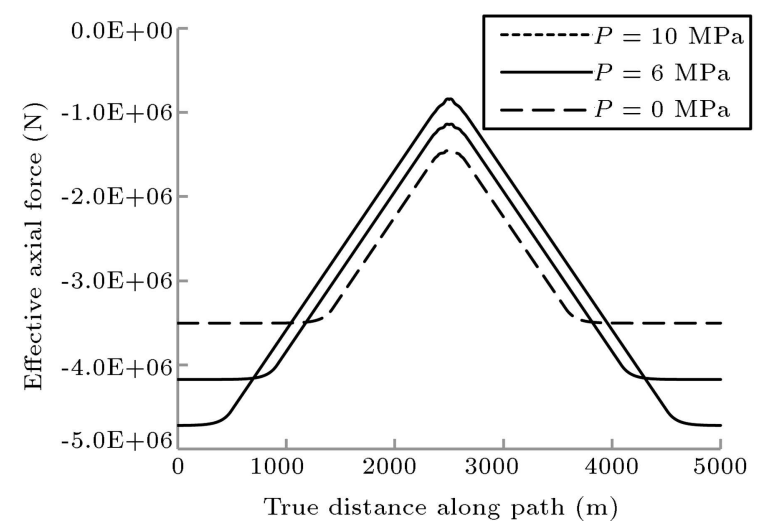

Figure 16. Effective axial force for different $P$.

decreases further, leading to higher increase in the axial expansion in the pipe. The maximum value of the axial expansion in the model without internal pressure is $0.17 \mathrm{~m}$; it is $0.37 \mathrm{~m}$ in the model with internal pressure equal to $6 \mathrm{MPa}$; it is $0.59 \mathrm{~m}$ in the model with internal pressure equal to $10 \mathrm{MPa}$. Axial expansion in the model with internal pressure equal to $10 \mathrm{MPa}$ is, respectively, 1.59 and 3.47 times higher than the models with internal pressure equal to $6 \mathrm{MPa}$ and without internal pressure.

Changes in the effective axial force at $60^{\circ} \mathrm{C}$ are shown in Figure 16. A further decrease in the effective axial force can be observed clearly in this figure. The effective axial force at the buckling point in the model without internal pressure is $1.45 \times 10^{6} \mathrm{~N}$; it is $1.13 \times$ $10^{6} \mathrm{~N}$ in the model with internal pressure equal to $6 \mathrm{MPa}$; it is $8.3 \times 10^{5} \mathrm{~N}$ in the model with internal pressure equal to $10 \mathrm{MPa}$. The effective axial force in the model with internal pressure equal to $10 \mathrm{MPa}$ has decreased respectively by $25 \%$ and $42 \%$, compared to the models with internal pressure equal to $6 \mathrm{MPa}$ and without internal pressure.

\subsubsection{Friction between the pipe and the seabed}

In the analysis of the buckling, the friction coefficient is a parameter of vital importance. The friction force is

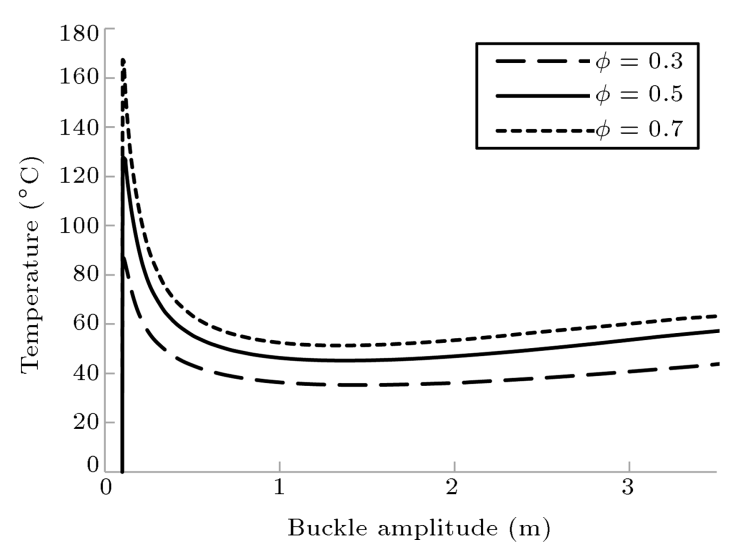

Figure 17. Temperature versus buckle amplitude for different $\phi$.

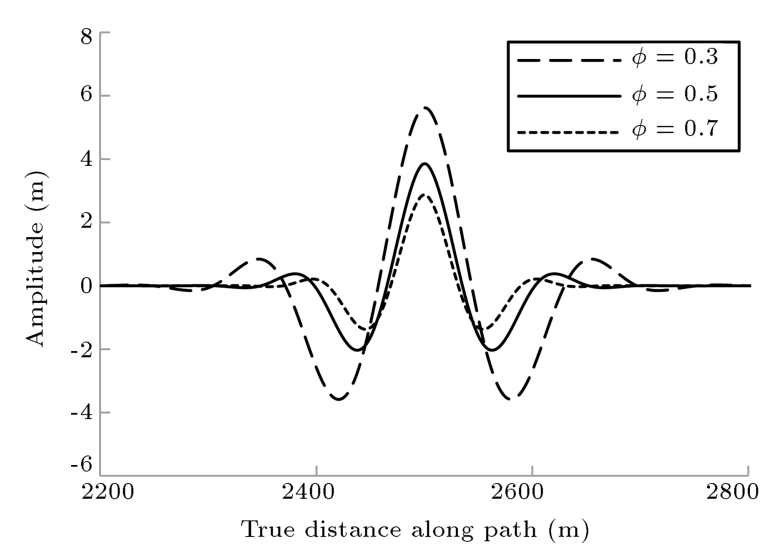

Figure 18. Pipe deformation for different $\phi$.

the only limitation in deformation of unburied pipelines and is used as a boundary condition in calculations. Therefore, the condition of friction coefficient has a great impact on the buckling characteristics. To identify the effects of friction coefficient on the lateral buckling of a pipeline on a rigid seabed, different friction coefficients $(0.7,0.5$, and 0.3$)$ with the assumption of equal friction at both axial and lateral directions are studied. Figure 17 shows that the safety temperature increases by increasing the friction coefficients. The safety temperature in the model with a friction coefficient equal to 0.5 is $45.15^{\circ} \mathrm{C}$, while in the model with friction coefficients equal 0.3 and 0.7 , safety temperatures are $35.29^{\circ} \mathrm{C}$ and $51.30^{\circ} \mathrm{C}$, respectively. In fact, safety temperature in the model with a 0.7 coefficient of friction has increased respectively by $13.6 \%$ and $50 \%$ compared to the models with 0.5 and 0.3 coefficients of friction. Changes in the buckling amplitude due to various coefficients of friction at $60^{\circ} \mathrm{C}$ are shown in Figure 18. According to this figure, the buckling amplitude and length decrease by increasing the friction coefficients. The buckling amplitude in the model with a friction coefficient equal to 0.3 is $5.62 \mathrm{~m}$; it is $3.85 \mathrm{~m}$ in the model with a friction coefficient equal to 0.5 , and it is $2.86 \mathrm{~m}$ in the model with a friction 


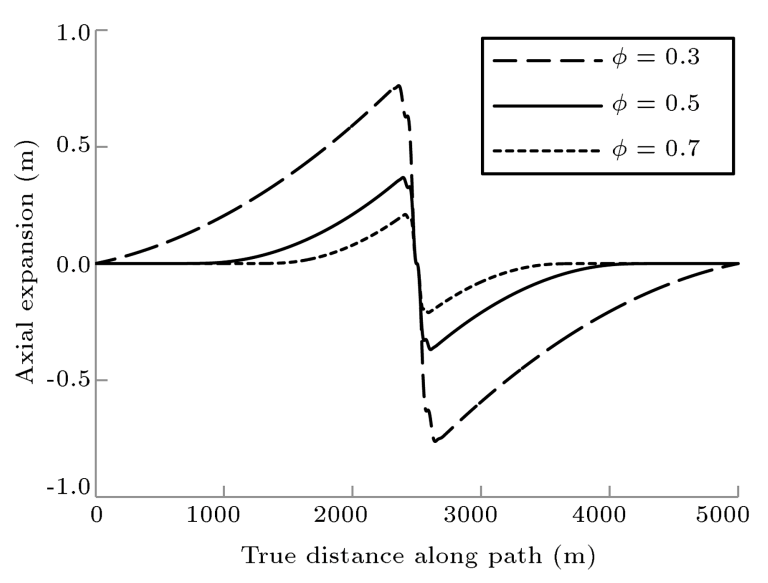

Figure 19. Axial expansion along pipe length for different $\phi$.

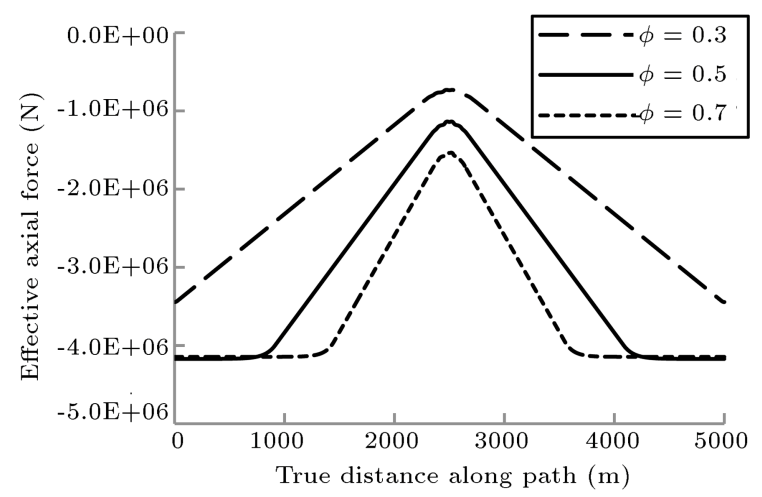

Figure 20. Effective axial force for different $\phi$.

coefficient equal to 0.7 . In fact, the buckling amplitude in the model with a friction coefficient equal to 0.3 is respectively 1.45 and 1.96 times higher than the models with friction coefficients equal to 0.5 and 0.7 .

The effect of the friction coefficient on the axial expansion at $60^{\circ} \mathrm{C}$ is shown in Figure 19. As seen in the figure, the axial expansion increases by decreasing the friction coefficient, because the buckling occurs at a lower temperature by decreasing the coefficient of the friction and, then, the effective axial force further decreases. In fact, the results indicate that the larger friction coefficients caused less possibility of pipeline buckles. The axial expansion in the model with a friction coefficient equal to 0.3 is $0.76 \mathrm{~m}$; it is $0.37 \mathrm{~m}$ in the model with a friction coefficient equal to 0.5 ; it is $0.21 \mathrm{~m}$ in the model with a friction coefficient equal to 0.7 . In fact, the axial expansion in the model with a 0.3 coefficient of friction is, respectively, 2.05 and 3.62 times higher than the models with 0.5 and 0.7 coefficients of friction. A further decrease in the effective axial force due to a decrease in the coefficient of friction at $60^{\circ} \mathrm{C}$ is shown in Figure 20. The effective axial force at the buckling point in the model with a friction coefficient equal to 0.3 is $7.14 \times 10^{5} \mathrm{~N}$; it is $1.13 \times 10^{6} \mathrm{~N}$ in the model with a friction coefficient
Table 5. Various initial imperfections.

\begin{tabular}{cc}
\hline $\begin{array}{c}\text { Imperfection } \\
\text { length } \\
(\mathbf{m})\end{array}$ & $\begin{array}{c}\text { Imperfection } \\
\text { amplitude } \\
(\mathbf{m})\end{array}$ \\
\hline 100 & 0.1 \\
100 & 0.3 \\
100 & 0.5 \\
100 & 0.7 \\
\hline
\end{tabular}

equal to 0.5 ; it is $1.53 \times 10^{6} \mathrm{~N}$ in the model with a friction coefficient equal to 0.7 . The effective axial force in the model with a friction coefficient equal to 0.3 has decreased, respectively, by $36.81 \%$ and $53.33 \%$, compared to the models with friction coefficients equal to 0.5 and 0.7 .

\subsubsection{Initial imperfection in the pipe}

Buckling can occur in the pipe due to the initial imperfection during pipe installation. In this section, a set of modeling results relevant to various structural imperfections based on Table 5 as well as the relevant deformations are presented to evaluate the effect of the initial imperfection on the lateral buckling. Figure 21 highlights different initial imperfection amplitudes versus the length of the pipe considered in the finiteelement simulations.

Figure 22 presents the temperature difference against the buckle amplitude curves. As already cited,

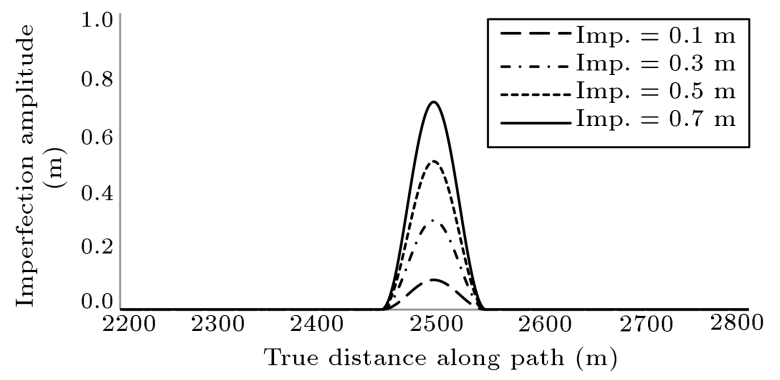

Figure 21. Initial horizontal out-of-straightness.

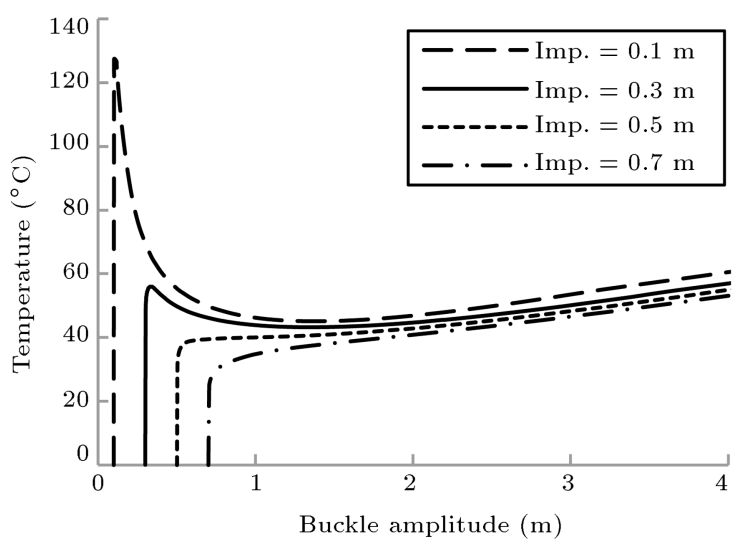

Figure 22. Temperature versus buckle amplitude for different imperfections. 


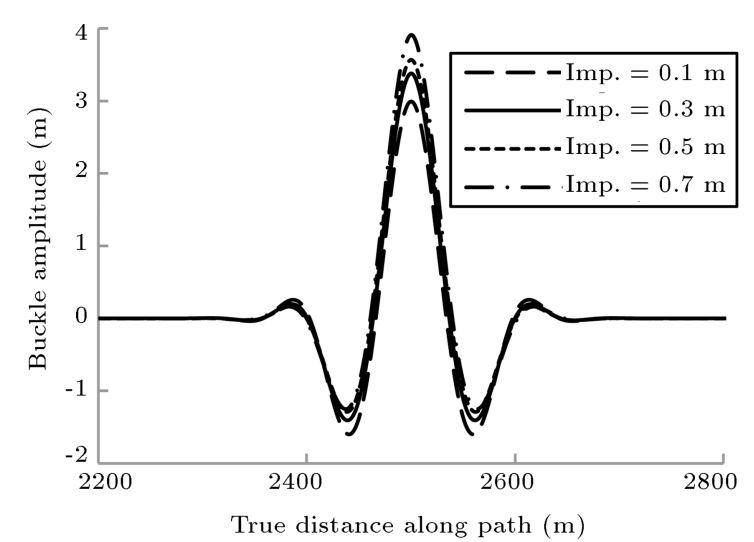

Figure 23. Pipe deformation for different imperfections.

the curves in Figure 22 look U-shaped. If the amplitude of the initial imperfection in the pipe is small, the temperature against the buckling amplitude curves in the pipeline with initial imperfection will be the same as the direct pipeline. In fact, for small initial imperfections, two stable and unstable equilibrium paths will be obtained. However, if the amplitude of the initial imperfection increases, the unstable equilibrium path changes significantly, so that only the stable equilibrium path (the post-buckling path) is obtained for the initial imperfection equal to $0.7 \mathrm{~m}$, i.e. the safety temperature also decreases by increasing the amplitude of the initial imperfection. In general, it can be stated that, at the same temperature difference, the likelihood of the lateral buckling increases in the pipeline with the larger amplitude of the initial imperfection. When the amplitudes of the initial imperfections are $0.1,0.3,0.5$, and $0.7 \mathrm{~m}$, the safety temperatures equal $45.15,43.21$, 39.15 , and $32.10^{\circ} \mathrm{C}$, respectively. In fact, the safety temperature in the model with the initial imperfection equal to $0.1 \mathrm{~m}$ has increased, respectively, by $4.49 \%$, $15.32 \%$, and $40.65 \%$ compared to the models with initial imperfections equal to $0.3,0.5$, and $0.7 \mathrm{~m}$.

Figure 23 details the relationship of the buckle amplitude versus the length of the pipeline for various initial imperfections at $55^{\circ} \mathrm{C}$ in the post-buckling path. The result indicates an increase in the amplitude of the buckling in the pipeline by increasing the initial imperfection amplitude. Length of the buckling does not change by increasing the initial imperfection amplitude. In other words, the length of the buckling is independent of the amplitude of the initial imperfection. The buckling amplitudes at $55^{\circ} \mathrm{C}$ in the models with the amplitudes of the initial imperfections equal to 0.1 , $0.3,0.5$, and $0.7 \mathrm{~m}$ are $2.85,3.20,3.57$, and $4.15 \mathrm{~m}$, respectively. In fact, the buckling amplitudes in the model with the initial imperfection's amplitude equal to 0.7 are $1.46,1.30$, and 1.16 times higher than those in the models with the initial imperfection's amplitudes equal to $0.5,0.3$ and 0.1 , respectively.

The effect of the initial imperfection on axial

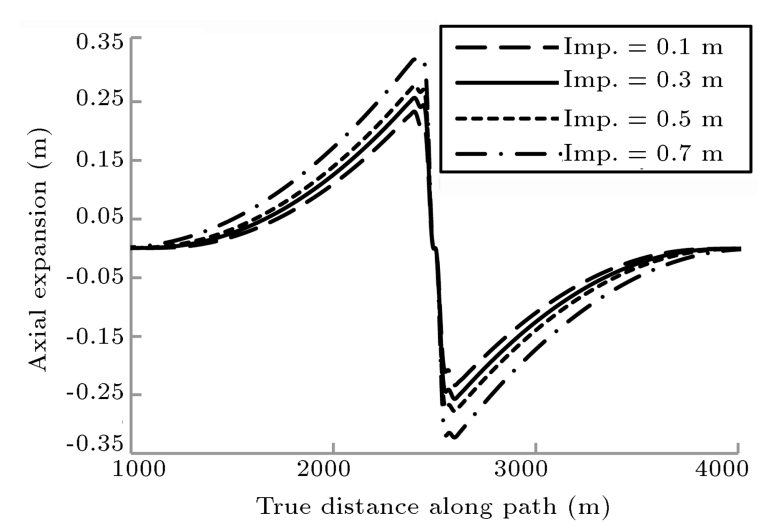

Figure 24. Axial extension along pipe length for different imperfections.

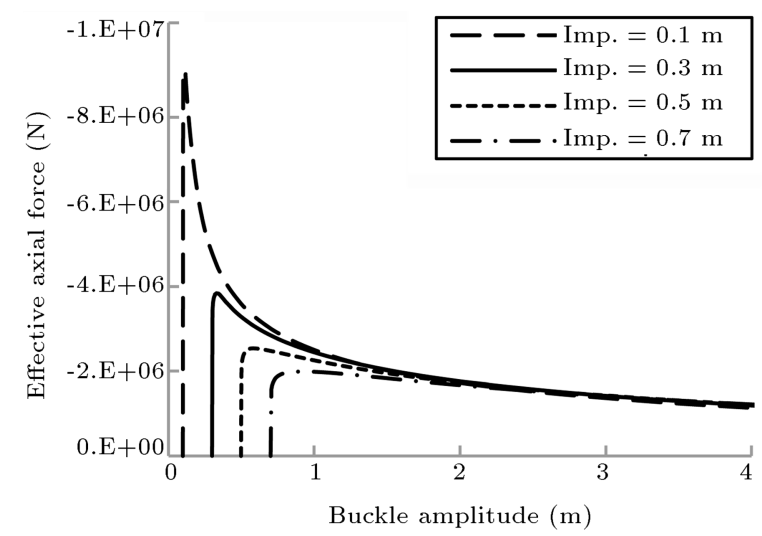

Figure 25. Effective axial force for different imperfections.

expansion at $55^{\circ} \mathrm{C}$ is shown in Figure 24. As can be seen in the figure, the axial expansion increases by increasing the initial imperfection amplitude, because the safety temperature decreases by increasing the initial imperfection. Initial out-of-straightness reduces the critical buckling force. Then, the pipe buckles at a lower compressive axial force; as a result, the axial expansion of the pipe will increase. Axial expansion rates at $55^{\circ} \mathrm{C}$ in the models with the initial imperfection's amplitudes equal to $0.1,0.3,0.5$, and $0.7 \mathrm{~m}$ are 0.21 , $0.24,0.27$, and $0.31 \mathrm{~m}$, respectively. In fact, the axial expansion in the model with the initial imperfection equal to $0.7 \mathrm{~m}$ has increased by $14.81 \%, 29.17 \%$, and $47.62 \%$ compared to the models with initial imperfections equal $0.5,0.3$, and $0.1 \mathrm{~m}$, respectively. Further initial out-of-straightness has greater influence on the buckling behavior of the pipeline.

Figure 25 shows the effective axial force versus the buckling amplitude. A decrease in the effective axial force is observed in the figure by increasing the amplitude of the initial imperfection. The maximum values of the effective axial force by increasing the initial imperfection's amplitudes are $9.11 \times 10^{6}, 3.84 \times$ $10^{6}, 2.54 \times 10^{6}$, and $1.99 \times 10^{6} \mathrm{~N}$. 


\subsubsection{Pipe diameter and thickness}

This section investigates the effect of pipe diameter and thickness on the lateral buckling of the pipeline on rigid seabed. For this reason, four pipe models with various diameters and thicknesses with the same ratio of diameter-to-thickness are used. The diameter-tothickness ratio in all of these pipes is equal to 43.3 . The properties of these pipes are presented in Table 6 .

Figure 26 shows the temperature versus the buckling amplitude curves for the lateral buckling of the pipe on rigid seabed for four models. According to the figure, it is observed that the safety temperature increases by increasing the pipe's diameter and thickness. In other words, it can be concluded that, at the same temperature difference, the likelihood of lateral buckling in the pipeline with a larger outer diameter and thickness is less than that of the pipeline with a smaller outer diameter and thickness. The safety temperatures of the model with outside diameters equal to $0.4 \mathrm{~m}$ and $0.65 \mathrm{~m}$ are $34.3^{\circ} \mathrm{C}$ and $45.15^{\circ} \mathrm{C}$, respectively; it is $50.28^{\circ} \mathrm{C}$ in the model with an outside diameter equal to $0.8 \mathrm{~m}$; it is $55.78^{\circ} \mathrm{C}$ in the model with an outside diameter equal to $0.9 \mathrm{~m}$. In fact, the safety temperature in the model with an outside diameter equal to $0.9 \mathrm{~m}$ has increased, respectively, by $62.62 \%, 23.54 \%$, and $10.94 \%$ compared to the models with outside diameters equal to $0.4,0.65$, and $0.8 \mathrm{~m}$.

The relationship between the buckle shape and the length of the pipelines with various diameters

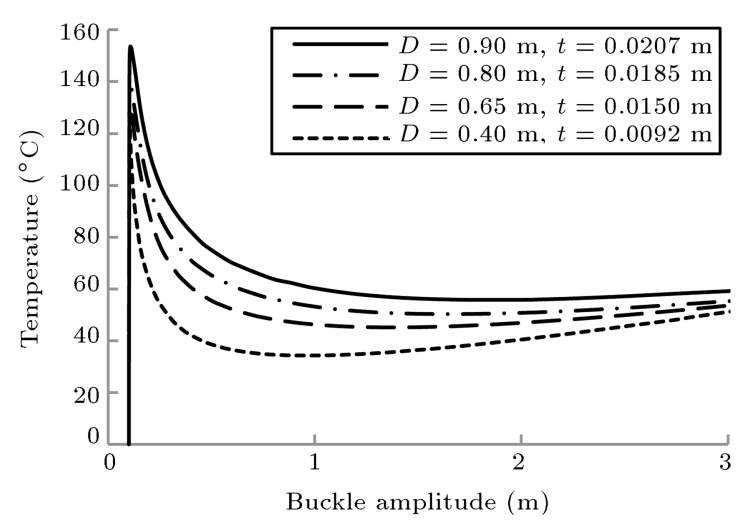

Figure 26. Temperature versus buckle amplitude for different $D$ and $t$. and thicknesses for $60^{\circ} \mathrm{C}$ in the post-buckling stage is shown in Figure 27. The results indicate that the buckling amplitude increases by decreasing the pipe's diameter and thickness. Buckling length also increases by increasing the diameter and thickness of pipe. The buckling amplitudes of the model by increasing the outside diameter are $4.00,3.85,3.38$, and $2.90 \mathrm{~m}$, meaning that the buckling amplitudes in the model with an outside diameter equal to 0.4 are $1.04,1.18$, and 1.37 higher than models with outside diameters equal to $0.65,0.8$, and 0.9 , respectively.

Figure 28 shows the axial expansion at $60^{\circ} \mathrm{C}$ to evaluate the effect of the outside diameter and thickness of the pipe. As observed in the figure, the axial expansion increases by decreasing the outside

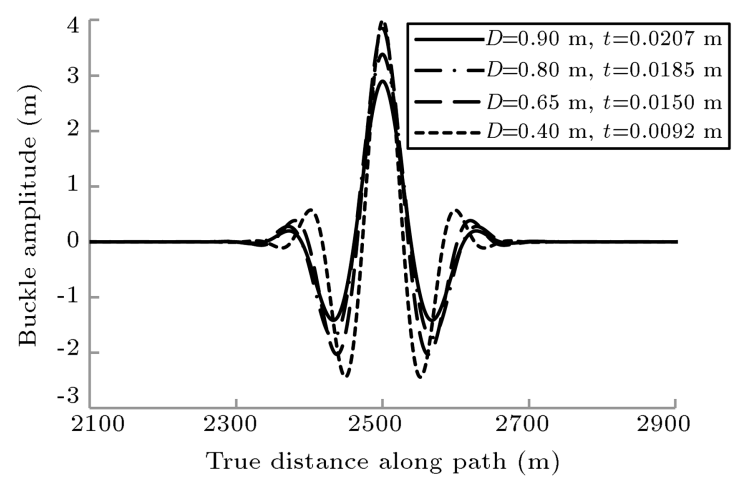

Figure 27. Pipe deformation for different $D$ and $t$.

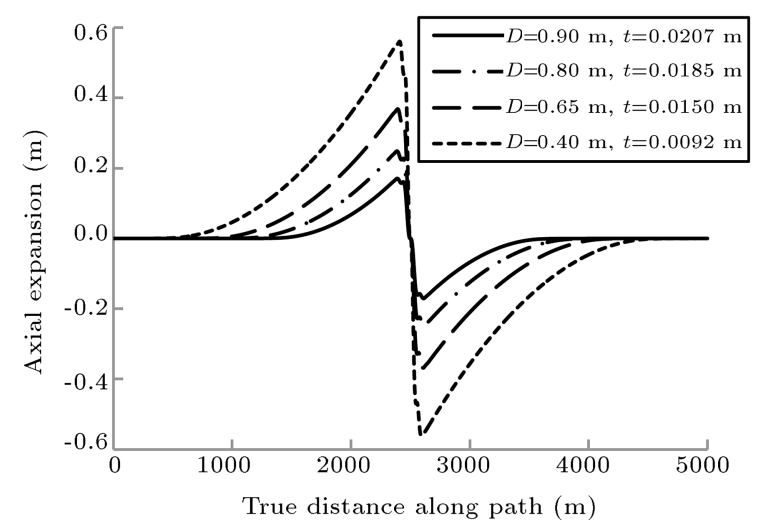

Figure 28. Axial expansion along pipe length for different $D$ and $t$.

Table 6. Properties of pipes in modelling.

\begin{tabular}{cccccc}
\hline $\begin{array}{c}\text { Pipe } \\
\text { material }\end{array}$ & $\begin{array}{c}\text { Outside } \\
\text { diameter } \\
(\mathbf{m})\end{array}$ & $\begin{array}{c}\text { Thickness } \\
\mathbf{( m )}\end{array}$ & $\begin{array}{c}\text { Yield } \\
\text { stress } \\
(\mathbf{M P a})\end{array}$ & $\begin{array}{c}\text { Ultimate } \\
\text { stress } \\
(\mathbf{M P a})\end{array}$ & $\begin{array}{c}\text { Mass } \\
\mathbf{d e n s i t y} \\
\left(\mathbf{k g} / \mathbf{m}^{\mathbf{3}} \mathbf{)}\right.\end{array}$ \\
\hline API X65 & 0.4 & 0.0092 & 448 & 531 & 7850 \\
API X65 & 0.65 & 0.015 & 448 & 531 & 7850 \\
API X65 & 0.8 & 0.0185 & 448 & 531 & 7850 \\
API X65 & 0.9 & 0.0207 & 448 & 531 & 7850 \\
\hline
\end{tabular}


diameter and thickness of the pipe, because the safety temperature reduces by decreasing the outside diameter and thickness of the pipe and the effective axial force reduces, too. The axial expansions by increasing the outside diameter are $0.56,0.37,0.25$, and $0.17 \mathrm{~m}$, respectively, meaning that the axial expansion rates in the model with an outside diameter equal to 0.4 are $1.51,2.24$, and 3.29 higher than those in models with outside diameters equal to $0.65,0.8$, and 0.9 , respectively.

The effective axial force versus the buckling amplitude is shown in Figure 29. A decrease in the effective axial force by reducing the outer diameter and thickness of the pipe is depicted in this figure. Decreasing the outer diameter and thickness of the pipe reduces the critical buckling load. Then, the pipe buckles at a lower compressive axial force. The maximum values of the effective axial force in the model with outside diameters equal to $0.4,0.65,0.8$, and 0.9 are $3.44 \times 10^{6}, 9.11 \times 10^{6}, 1.52 \times 10^{7}$, and $2.11 \times 10^{7} \mathrm{~N}$, respectively.

\subsubsection{Pipe's material}

As previously mentioned, one of the most important parameters of the design of offshore pipelines is the material of the pipe. Therefore, the effect of the pipe's material on the lateral buckling of the pipelines on rigid seabed is investigated. To investigate the impact of the pipe's material, two grades of steel are used. Their properties are shown in Table 7 . The stress-train curves of X65-grade and X80-grade pipes are assumed, as shown in Figure 30.

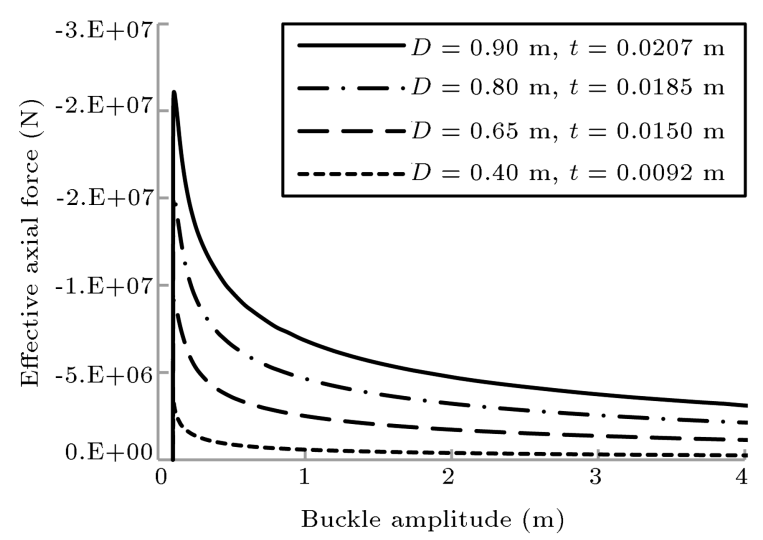

Figure 29. Effective axial force for different $D$ and $t$.

Table 7. Properties of pipes in modelling.

\begin{tabular}{ccccc}
\hline $\begin{array}{c}\text { Pipe } \\
\text { material }\end{array}$ & $\begin{array}{c}\text { Outside } \\
\text { diameter } \\
(\mathbf{m})\end{array}$ & $\begin{array}{c}\text { Thickness } \\
(\mathbf{m})\end{array}$ & $\begin{array}{c}\text { Yield } \\
\text { stress } \\
(\mathbf{M P a})\end{array}$ & $\begin{array}{c}\text { Ultimate } \\
\text { stress } \\
(\mathbf{M P a})\end{array}$ \\
\hline API X65 & 0.65 & 0.015 & 448 & 531 \\
API X80 & 0.65 & 0.015 & 448 & 531 \\
\hline
\end{tabular}

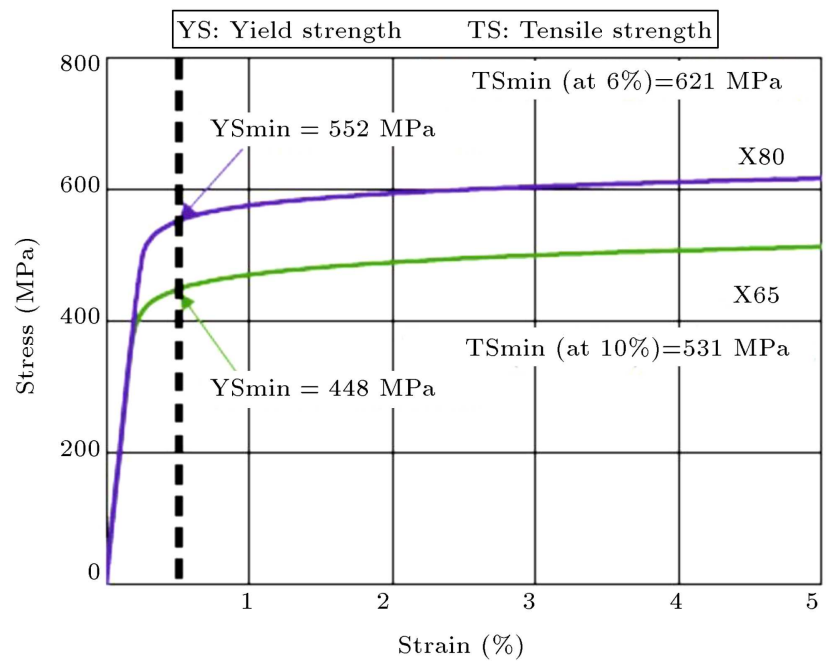

Figure 30. Stress-strain curves for conventional steel pipes X65 and X80 [22].

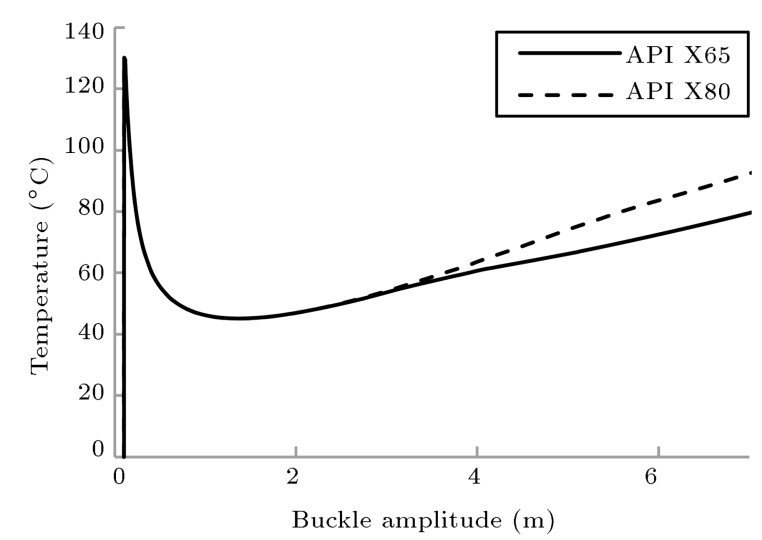

Figure 31. Temperature versus buckle amplitude for steel pipes: X65 and X80.

Figure 31 shows the temperature difference versus the buckling amplitude for the lateral buckling of the pipeline on rigid seabed for two models. According to this figure, it is observed that the unstable equilibrium path does not change by changing the steel grade. In addition, the safety temperature is the same for both types of steel. The only difference is observed in the post-buckling stage or the stable equilibrium path. In other words, it can be concluded that, at the same temperature difference, the likelihood of lateral buckling is the same for both types of steel. The temperature to start buckling in both models is $45.14^{\circ} \mathrm{C}$. The behavior of the pipe is different only at temperatures higher than the safety temperature. The buckling amplitude against the length of the pipelines for $80^{\circ} \mathrm{C}$ in the post-buckling stage is shown in Figure 32. The result indicates that the buckling amplitude increases in the pipe after the beginning of buckling by increasing the temperature in the steel pipe with lower yield stress, compared to the steel pipe with greater yield stress. The buckling amplitude at $80^{\circ} \mathrm{C}$ 


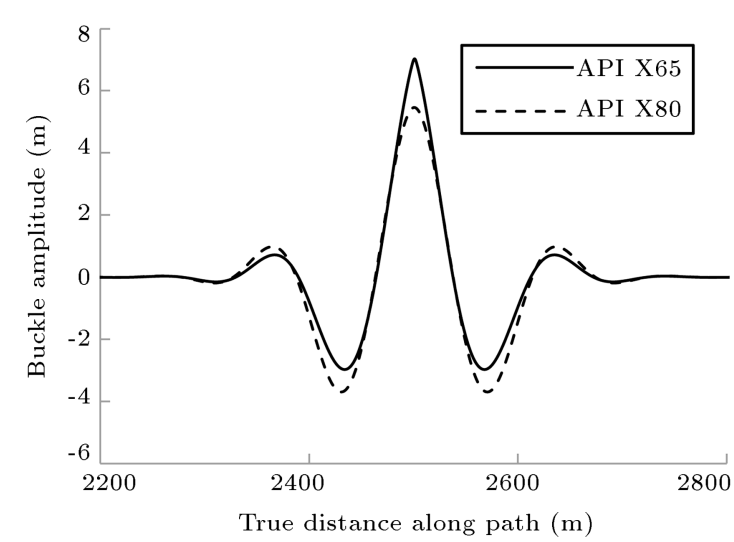

Figure 32. Pipe deformation for steel pipes: X65 and $\mathrm{X} 80$.

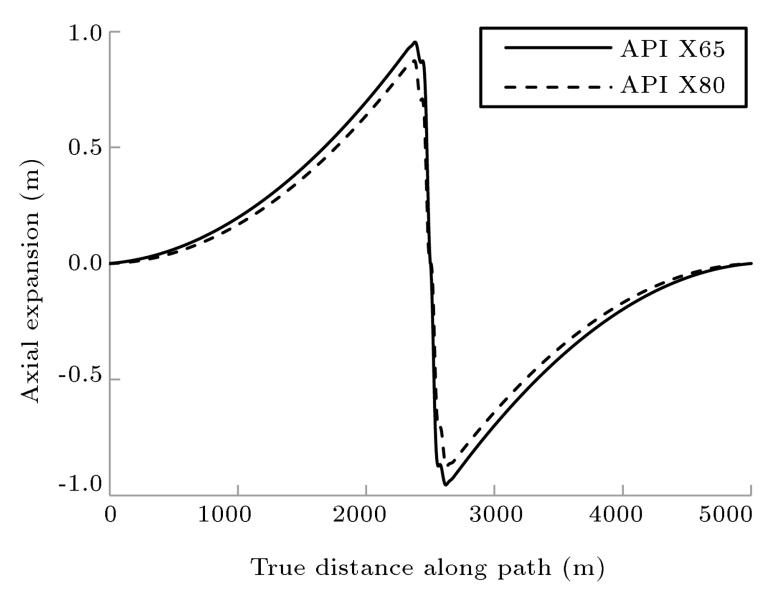

Figure 33. Axial expansion along pipe length for steel pipes: X65 and X80.

in the pipe with lower yield stress is equal to $6.96 \mathrm{~m}$, while this value is equal to $5.44 \mathrm{~m}$ in the steel pipe with greater yield stress. The buckling amplitude at the temperature of $80^{\circ} \mathrm{C}$ in the $\mathrm{X} 65$-grade pipe increases $27.94 \%$ higher than that in the X80-grade pipe. The length of buckling does not change by changing the type of steel as it can be seen in the figure. In other words, the length of buckling is independent of the selected steel type.

The axial expansion at $80^{\circ} \mathrm{C}$ to examine the effect of the type of steel is shown in Figure 33. As seen in the figure, the axial expansion in the steel pipe with lower yield stress slightly increases, as compared to steel pipe with greater yield stress. As a result, the effective axial force further decreases in the pipe. The axial expansion in steel with lower yield is equal to $0.95 \mathrm{~m}$, while this value is equal to 0.87 in the steel with greater yield stress. The axial expansion of the X65-grade pipe at $80^{\circ} \mathrm{C}$ increases 1.09 times higher than that of the $\mathrm{X} 80$-grade pipe. The effective axial force versus the length of the pipe at $80^{\circ} \mathrm{C}$ is shown in Figure 34. The effective axial force in the steel pipe with lower yield stress slightly decreases, as compared

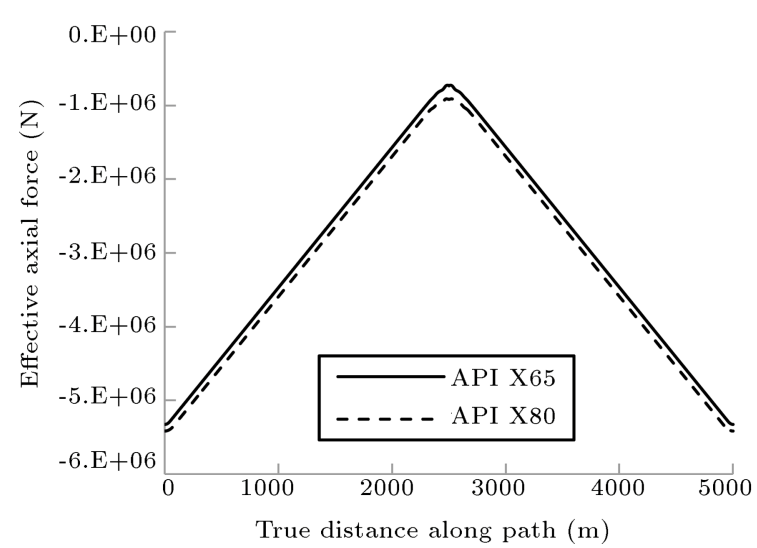

Figure 34. Effective axial force for steel pipes: X65 and X80.

to the steel pipe with greater yield stress. Then, the pipe buckles at lower compressive axial force. The effective axial forces of the X65- and X80-grade pipes are $7.32 \times 10^{5} \mathrm{~N}$ and $9.17 \times 10^{5} \mathrm{~N}$, respectively. The effective axial force of the X65-grade pipe has increased by $25.27 \%$, as compared to X80-grade pipe.

\section{Conclusions}

This study investigated and discussed the lateral buckling of the pipelines on rigid seabed under the temperature and internal pressure using ABAQUS software. The influence of the effective parameters on the lateral buckling of the pipelines was evaluated. Overall, lateral buckling occurred in pipelines with higher internal pressure, larger diameters and thicknesses, larger soil resistance coefficients, and larger initial imperfection amplitudes. By increasing yield stress, the likelihood of lateral buckling was the same for both types of steel, leading to better post-buckling behavior of the steel pipe. The main results in the range of variation of the parameters are as follows:

- In the lateral buckling of the pipelines on rigid seabed under temperature and internal pressure, mode 3 is clearly the most critical one at some $88 \%$ of yield. In addition, maximum buckle amplitude and maximum bending stress occur in this mode;

- The effective axial force decreases during analysis following the occurrence of the buckling in the pipeline; however, the effective axial force at the farther point to buckling is proportional to temperature along the length of the pipeline. In fact, the value of this force decreases by decreasing the temperature (unstable equilibrium path), while it increases by increasing the temperature;

- By increasing the internal pressure, due to reduction in the safety temperature, the lateral buckling is more likely to occur. The buckling amplitude and buckling Length will increase. Safety temperatures 
in the model without internal pressure has increased, respectively, by $21 \%$ and $40 \%$, as compared to the models with internal pressures equal to $6 \mathrm{MPa}$ and $10 \mathrm{MPa}$. The axial expansion also increases by increasing the pressure;

- The safety temperature increases and the buckling amplitude and length decrease by increasing the friction coefficients. The axial expansion also increases by decreasing pressure. In fact, based on the results' details, the larger friction coefficient caused low possibility of pipeline buckling. Thus, it would be prudent to reduce the design temperature change or to prevent lateral buckling by raising the effective friction coefficient, perhaps by trenching the line;

- For small-sized initial imperfections, two stable and unstable equilibrium paths will be obtained. However, if the amplitude of the initial imperfection increases, only the stable equilibrium path (postbuckling path) is obtained. The safety temperature decreases and the buckling length increases by increasing amplitude of the initial imperfection. Initial out-of-straightness reduces critical buckling force. Then, the pipe buckles at lower compressive axial force; as a result, axial expansion of the pipe will increase;

- The safety temperature increases by increasing the pipe's diameter and thickness. The results also indicate that the buckling amplitude and buckling length increase by decreasing the pipe's diameter and thickness. The axial expansion increases by decreasing outside diameter and thickness;

- The unstable equilibrium path does not change by changing the steel grade at the same temperature difference. In addition, the safety temperature is the same for both types of steel, and the likelihood of lateral buckling is the same for both types of steel. In general, we can say that by increasing the yield stress, the steel pipe shows better postbuckling behavior.

\section{References}

1. C-CORE. "Design options for offshore pipelines in the US Beaufort and Chukchi Seas", $C$-CORE Report $R$ 07-078-519 v-2, Ottawa, Canada, prepared for: US Department of the Interior Minerals Management Service (2008).

2. Liu, R. and Yan, S.H. "A brief history of upheaval buckling studies for subsea buried pipeline", Journal of Pipeline Systems Engineering and Practice, 4(3), pp. 1949-1204 (2012).

3. Kerr, A.D. "Analysis of thermal track buckling in the lateral plane", Acta Mechanica, 30(1-2), pp. 17-50 (1978).
4. Hobbs, R.E. "Pipeline buckling caused by axial loads", Journal of Constructional Steel Research, 1(2), pp. 210 (1981).

5. Hobbs, R.E. "In-service buckling of heated pipelines", Journal of Transportation Engineering, 110(2), pp. 175-189 (1984).

6. Taylor, N. and Gan, A.B. "Submarine pipeline buckling-imperfection study", Thin-Walled Structures, 4(4), pp. 295-323 (1986).

7. Palmer, A.C., Elliance, C.P., Richards, D.M., and Guijt, J. "Design of submarine pipelines against upheaval buckling", Proceeding of 22nd Offshore Technology Conference, 1, Houston, USA, pp. 551-560 (1990).

8. Peek, R. and Yun, H. "Flotation to trigger lateral buckles in pipelines on a flat seabed", Journal of Engineering Mechanics, 133(4), pp. 442-451 (2007).

9. Wang, L., Ruowei, S.H., Feng, Y., Zhen, G., and Luqing, Y. "Global buckling of pipelines in the vertical plane with a soft seabed", Applied Ocean Research, 33(2), pp. 130-136 (2011).

10. Karampour, H., Albermani, F., and Gross, J. "On lateral and upheaval buckling of subsea pipelines", Engineering Structures, 52, pp. 317-330 (2013).

11. Liu, R., Xiong, H., Wu, X., and Yan, S. "Numerical studies on global buckling of subsea pipelines", Ocean Engineering, 78, pp. 62-72 (2014).

12. Karampour, H. and Albermani, F. "Experimental and numerical investigations of buckle interaction in subsea pipelines", Engineering Structures, 66, pp. 8188 (2014).

13. Wang, L., Shi, R., Yuan, F., Guo, Z., and Yu, L. "Global buckling of pipelines in the vertical plane with a soft seabed", Applied Ocean Research, 33(2), pp. 130-136 (2011).

14. Hong, Z., Liu, R., Liu, W., and Yan, S. "A lateral global buckling failure envelope for a high temperature and high pressure (HT/HP) submarine pipeline", Applied Ocean Research, 51, pp. 117-128 (2015).

15. Feng, X., Wu, W., Li, X., Zhang, X., and Zhou, J. "Experimental investigations on detecting lateral buckling for subsea pipelines with distributed fiber optic sensors", Smart Structures and Systems, 15(2), pp. $245-258$ (2015).

16. Li, G., Zhan, L., and Li, H. "An analytical solution to lateral buckling control of subsea pipelines by distributed buoyancy sections", Thin-Walled Structures, 107, pp. 221-230 (2016).

17. Shahandeh, R. and Showkati, H. "Influence of ringstiffeners on buckling behavior of pipelines under hydrostatic pressure", Journal of Constructional Steel Research, 121, pp. 237-252 (2016).

18. Zhang, X., Duan, M., Wang, Y., and Li, T. "Parameters study on lateral buckling of submarine PIP pipelines", Ocean Systems Engineering, 6, pp. 99-115 (2016). 
19. Reda, A.M. and Forbes, G.L. "Investigation into the dynamic effects of lateral buckling of high temperature/high pressure offshore pipelines", Proceedings of the Annual Conference of the Australian Acoustical Society, 1, Fremantle, Australia, pp. 1-11 (2012).

20. ABAQUS 6.10. "Abaqus/CAE user's manual", Dassault Systémes Simulia, Providence, USA (2011).

21. Veritas, D.N. "Global buckling of submarine pipelinesstructural design due to high temperature/high pressure", Recommended Practice, DNV RP-F110, Veritasveien, Norway (2007).

22. Suzuki, N., Igi, S., and Masamura, K. "Seismic integrity of high-strength pipelines", JFE Technical Report, 17, pp. 14-19 (2008).

\section{Biographies}

Mohammad Vaghefi was born in Shiraz, Iran in 1973. He earned BSc and MSc degrees in Civil Engineering from Shiraz University, Iran in 1997 and 1999, respectively, and a $\mathrm{PhD}$ degree from Tarbiat Modares University, Tehran, Iran in 2009. He is currently an Associate Professor of Civil Engineering at Persian Gulf University, Bushehr, Iran. His areas of interest include hydraulic engineering, pipelines, fluid mechanics, open channel hydraulics, river engineering, water flow engineering, hydrodynamics, and hydraulic structures. He has presented 220 papers at national and international conferences and has published 100 journal papers.

Marjan Keshavarzi was born in Bushehr, Iran in 1985. She earned BS degree in Civil Engineering from Persian Gulf University in 2008 and MSc degree from Islamic Azad University, Bushehr, Iran in 2014. She is currently a Lecturer of Vocational Department, Alzahra University, Bushehr, Iran. Her major research interests are focused on pipelines, hydraulic structures, fluid mechanics, and hydrodynamics, especially in terms of numerical modelling. She is the author and co-author of 5 papers published in journals or presented at conferences.

Maryam Akbari was born in Bushehr, Iran in 1989. She earned BSc and MSc degrees in Civil Engineering from Persian Gulf University, Bushehr, Iran in 2012 and 2015, correspondingly. She is currently a Lecturer of Civil Engineering Department, Persian Gulf University. Her research interests are in the areas of hydraulic structures, fluid mechanics, open channel hydraulics, water flow engineering, and hydrodynamics. She is the author and co-author of 20 published papers in journals and presented at national and international conferences. 